\title{
Inhalt
}

Vorwort

\section{Definitionen der Grenze}

Jörn Garber

Die „Schere im Kopf“ des Autors

Anthropomorphe Bewußtseinsgrenzen von Erfahrung (Georg Forster)

Merio Scattola

Die Grenze der Neuzeit

Ihr Begriff in der juristischen und politischen Literatur

der Antike und Frühmoderne

Frank Ebeling

Die Grenze in der Betrachtung der Geopolitik in Deutschland

Andreas Jung

Der Aufhalter des Bösen

Carl Schmitt und die Grenze

Jan Assmann

Israel und Ägypten -

Grenzen auf der Landkarte der Erinnerung

Heidi de Mare

Räumliche Markierungen holländischer Identität

Das grenzenlose Interesse von Simon Stevin und Jacob Cats

an Grenzen und Grenzübergängen

II. Verhaltenslehren der Grenze

Thomas Kappe

Anmerkungen zu einer Biologie der Grenze 
Mark Münzel

Indianische Wanderungen über Grenzen des Diesseits hinaus

New Age und die Suche der Guaraní nach dem Land ohne Schlechtes

Ulrich Schütte

Stadttor und Hausschwelle

Zur rituellen Bedeutung architektonischer Grenzen in der Frühen Neuzeit

Thomas Rahn

Grenz-Situationen des Zeremoniells in der Frühen Neuzeit

Markus Bauer

Mythos und Sachlichkeit -

Beobachtungen zur Grenze in der Exilliteratur

III. Ästhetische Fassungen der Grenze

Wolfgang Kemp

Die Mauern und Tore von Nancy und Potsdam

Über Stadtgrenzen, vor allem im 17. und 18. Jahrhundert

Gert Mattenklott

Entgrenzungen

Die Mauer im Museum 255

Cornelia Jöchner

Stadt, Land, Garten, Fluß -

Die Ausdehnung und Öffnung des geometrischen Gartens

Melissa Thorson Hause

Konkurrierende Grenzen

Text, Bild und Raumvorstellung in De limitibus constituendis

des Hyginus Gromaticus

Helmut Mottel

Hölderlins Übertrittsrituale

Ein existentielles Paradox im Buchstabenbild

Albrecht Koschorke

Der postmortale Blick -

Das Erhabene und die Apokalypse

Personenverzeichnis

Biobibliographische Notizen 